\title{
USING CONCRETE MODEL TO ENHANCE CONCEPTUAL KNOWLEDGE OF LOW ABILITY STUDENTS IN FACTORISING QUADRATIC EXPRESSION
}

\author{
Eis Farhana Abdul Latiff ${ }^{1}$, Khairul Amilin Tengah ${ }^{2}$, \\ Masitah Shahrill ${ }^{3}$ and Elvynna Leong ${ }^{4}$ \\ ${ }_{1,2,3}$ Al-Falaah Primary School, Brunei Darussalam, Brunei \\ ${ }^{4}$ Faculty of Science, Universiti Brunei Darussalam, Brunei
}

\begin{abstract}
This action research focused on the use of concrete models in the teaching and learning of factorisation by participants from Year 10 low ability classes in Brunei. The study attempts to assist students' difficulties in learning algebra, specifically on factorising quadratic expressions with all positive coefficients by using simplified algebraic tile as a form of concrete manipulative to aid teaching and learning. These tiles act as the remedial approach to improve students' conceptual knowledge. Result analysis of 22 students indicated significant difference between the means of pre and post-tests students' results using t-test, suggesting that the implementation of concrete model does have an effect on students' achievements, and could possibly be used as an alternative approach to teaching this topic. There were also some positive feedback and concerns raised by students on the use of concrete models in their factorisation learning based on the interview of selected students in the study.
\end{abstract}

Keywords: Manipulatives, Algebraic Tile,Factorization, Quadratic Expression

\section{Introduction}

The secondary school students in Brunei Darussalam are usually taught using 'drilling and practice' method which focuses more on the preparation for test or examination (Badarudin and Khalid, 2008). Badarudin and colleague claimed that most teachers felt they were judged based on their students' examination results, pressuring them to cover all syllabuses as quickly as possible to prepare students for tests and examinations. Due to this norm, teachers had limited time to teach students on the conceptual knowledge despite agreeing of its importance.

A new educational system known as the National Education System for the $21^{\text {st }}$ Century or SistemPendidikan Negara Abad ke-21 (SPN 21) was introduced in 2008 by the Ministry of Education of Brunei (Ministy of Education, 2012). In order to achieve one of the aim stated in the SPN21 handbook (i.e. to develop $21^{\text {st }}$ century skills amongst our students), the Ministry of Education has set up three main learning domains that teachers should focus on and implement into their classroom practices; knowledge and understanding, essential skills, and, attitudes and values. Thus, lessons planning need to emphasise more on enriching students' conceptual knowledge through different teaching approaches for the better development of mathematical understanding.

During her child psychology courses, Robert (2010) learned that one's learning develops from the concrete to the semi concrete, or representational, and finally to the abstract or symbolic level. When this learning theory is applied to mathematics, the use of manipulatives and hands-on learning experiences should precede procedural symbol manipulation, which leads to her belief that using manipulatives could enhance students' conceptual knowledge on abstract representations.

According to Moyer (2001), manipulative models, invented to purposely represent explicitly and concretely

Corresponding Author:EisFarhana Abdul Latiff/eisfarhana.latiff@ hotmail.com

$3^{\text {rd }}$ International Conference on Education, 20-22 April 2017, Kuala Lumpur, Malaysia 
mathematical ideas that are abstract, enable students to be actively involved in the lesson through hands-on experiences. This supports McClung's (1998) suggestion that incorporating the use of concrete model is one of the strategies to enrich instructional activities that will produce optimal results in the algebra lesson.

\section{Need and significance of the study}

Several studies in the use of manipulative in algebra classrooms have resulted in mixed results. On a positive outcome, a study by Hinzman (1997) indicated the use of manipulative enhanced students' learning and increased students' confidence towards their learning with manipulative materials. On the other hand, McClung (1998) found that students who did not use manipulative outperformed those taught with manipulative. This study will provide mathematics teachers the option to utilise the application of concrete model in their classroom activities to meet diverse students' learning needs in mathematics classroom, particularly dealing with weaker students at secondary level.

\section{Purpose of the Study}

The purpose of this study is to use concrete model, 'Algebraic Tile' as a remedial approach to improve students' difficulties in learning algebra specifically on factorising quadratic expression with all positive coefficients. Majority of the students in Brunei, especially the low ability ones, find it difficult to apply the crossmultiplication method that is commonly used when attempting questions on factorisation of quadratic expression. Therefore, the algebra tiles act as an alternative approach in attempting such questions, or as a bridge concept to connect and explain the cross-multiplication method.

\section{Research Questions}

These research questions were used to guide this study:

1. How does the aid of concrete model affect low ability students' performance on factorising quadratic expression in Brunei Darussalam?

2. What are students' perceptions on the usefulness and effectiveness of concrete model in learning factorisation of quadratic expression in Brunei Darussalam?

\section{Review of Literature}

\section{Students' Difficulties in Learning Factorisation of Quadratic Expression}

Kotsopoulos (2007) reported that majority of her secondary mathematics students stated learning quadratics is one of the most conceptually challenging topics, and she observed those who have difficulty with basic multiplication table fact retrieval will also face difficulty in factorisation of quadratics effectively, since they are interlinked. Other challenge experienced by students is the ability to recognise and understand varied representations of the same quadratic relationship.

Recent study by Yahya and Shahrill (2014) on the strategies used in solving algebra by secondary school Year 11 repeating students in Brunei, categorised four main themes of students' errors; errors on understanding factorising quadratic expression, errors on multiplication of factors, errors on addition of integers, and, errors on the formation of solution for factorisation. They found that: students struggled to define the term as they could not put common terms or linear expression in brackets; students have lack of fundamental concept in distinguishing the terms; students used incorrect terms in determining factors; and several errors on adding negative integers. The researchers also discovered that students' answers reflected rote learning and a lack of relational understanding. 


\section{Concrete Model as a Remedial Approach to Students' Learning}

Pepperset al. (2014) conducted an action research lessons with an eighth-grade pre-algebra, designed on conceptual understanding for mathematical proficiency of fractions, including fraction equivalences, ordering fractions, and dividing and multiplying fractions. Positive result was achieved through incorporation of concrete and virtual manipulative into the classroom activities throughout the year. Improvements were also observed in students' attitudes toward math, their ability to communicate their understanding and subsequently, their ability to build on the knowledge gained during the intervention lessons. Overall, students showed positive reactions to both types of manipulative.

Shaw (2002) acknowledged the utilising manipulative and visual representations in mathematics classroomenabled students to represent their mathematical ideas in multiple ways and subsequently, developed their conceptual understanding. Thus, with clearer understanding, students' misconception could be minimised and develop the sense of 'ownership' of knowledge. She believed that if students fully understand a certain concept in their learning, then anxiety of the subject is lessened, and encourage students to communicate mathematical ideas and concepts confidently through discussion with their teacher and peers.

However, manipulative should be used correctly in order to achieve successful outcomes (Bogganet al., 2010). They highlighted the importance of understanding the mathematical concept beforehand so that the learning goals and objectives could be met with the effective use of correct manipulatives.

\section{Teachers' Views about using Concrete Model in Mathematics Instruction}

There are some studies done on investigating teachers' views about using concrete model and other types of manipulative in their mathematics classroom. Gulkilik and Arikan (2012) conducted a study on determining preservice secondary mathematics teachers' views on manipulative. From the results, the researchers concluded that pre-service teachers had some concerns about the usage of manipulative such as time consuming, lack of technological infrastructure in classrooms and lastly, students' and parents' expectations about university entrance exam. Therefore, the teachers did not bother and avoid using manipulative in their lessons.

\section{Methodology}

The study adopted an action research approach through qualitative and quantitative methods, using concrete manipulative of simplified algebraic tiles as part of the intervention lessons. Convenient sampling of two weak classes in Year 10 in one of the all-boys secondary schools in Brunei-Muara District. In Brunei's SPN21 education system, all students follow a common curriculum fromYear 7, and then channelled, based on their Student Progress Assessment (SPA) results at the end of year 8, to either General Secondary Education Programme or Applied Secondary Education Programme. The two classes (group I and II) chosen are from the Applied Secondary Education Programme and will sit for their International General Certificate of Secondary Education (IGCSE) Examination the following year of their study. In terms of mathematical competencies and skills, both classes are within the same range of ability and the participants are categorised into the low ability group. A total of 42 students were initially involved in the study, however due to absenteeism either on the preor post-test, only 22 students were considered in the analysis of this study.

The selected topic for this research study was factorisation of algebraic quadratic expression. Due to the limitation on the features of the simplified version of algebra tiles, this study will only focus on factorising quadratic expression with positive coefficients, i.e. $a x^{2}+b x+c$ where $a, b$ and $c$ are positive constants. The two-dimensional model is made from white paper, which comprised of three different sets of 4-sided shapes as shown in Figure 1 to represent the "one" unit, $x$ and $x^{2}$. It should be noted that side with $x$ was not multiple of "one" (in this case it was 4.5 of 1 ) to ensure that corresponding 1 (and $x$ ) will only align with 1 (and $x$ ). 


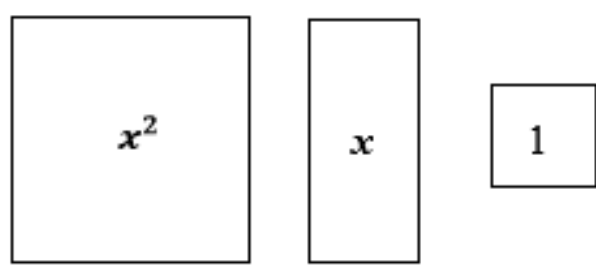

Figure 1 Algebra Tiles

Prior to the intervention lessons, pre-test was carried out in order to review the students' prior knowledge and identify their basic algebraic factorisationknowledge. The pre-test questions consisted of six items and students were given thirty minutes to complete them. These students are allowed to use calculators during the test to avoid the effect of calculation error in this study.

Both classes went through two phases of intervention lessons. In the first lesson, the introduction on the concept of factorisation and revision on cross-multiplication method, followed by the introduction of factorisation using algebra tiles were carried out. Each set of algebra tiles were distributed to every student. The teacher first demonstrated, using two examples of quadratic expression, how to rearrange algebra tiles to get a rectangular shape in order to find its length and breadth as the factors of the expression. Class activity then followed where students were required to rearrange algebra tiles on their own. They had to draw the patterns (arrangements) for each quadratic expression and as the final step, evaluate the lengths and breadths.

On the last day of intervention, the students had to demonstrate three possible patterns for the assigned quadratic expression. The purpose was to make them realise that no matter how many different patterns they came up with, they would still get the same answer. At the same time, their teacher would be able to correct any students' mistakes and discuss their findings with the whole class, in addition to reinforcement of the intervention concept.

At the end of the intervention lesson, post-test was conducted in order to determine if there was any improvement on students' learning after utilising the concrete model in their classroom practices. Unlike in the intervention lessons, only one group was supplemented with algebra tiles during this test while the other group had to depend solely on their understanding from the intervention practices.Both pre-test and post-test consisted of the same questions on factorisation algebraic expression with positive coefficient, gradually increasing in terms of difficulties, with the last two items involving higher coefficients of $x^{2}$ as shown in Table 1.

Table 1 Items in pre- and post-test

\begin{tabular}{lc}
\hline Item number & Question \\
\hline 1 & $x^{2}+x$ \\
\hline 2 & $x^{2}+2 x+1$ \\
\hline 3 & $x^{2}+5 x+6$ \\
\hline 4 & $x^{2}+7 x+12$ \\
\hline 5 & $2 x^{2}+3 x+1$ \\
\hline 6 & $3 x^{2}+5 x+2$ \\
\hline
\end{tabular}

As suggested by Cohen and Crabtree (2006), semi-structured interviews were conducted on selected students to provide reliable and comparable qualitative information. Random sample of 6 students from each group were selected for interview to further explore participants' thoughts on the usefulness and effectiveness of learning factorisation with algebra tiles. The interviews concentrated on three aspects: how do you find mathematics in 
general; how did you feel when you first encounter algebra tiles; and why did you prefer algebra tiles/crossmultiplication method.

Students' scores in pre- and post- tests were analysed through paired sample t-test using SPSS Statistics 22 software to identify any significant difference in the scores in order to determine whether the intervention on utilising algebra tiles in learning factorisation has an effect on students' performance. In addition, students' preferred options in attempting post-test questions were also analysed. The semi-structured interview of selected students were transcribed, coded and analysed for emerging themes.

\section{Results and Discussion}

Due to student absentees during the data collection period, only the results from 22 students were taken into account; 9 students from group I and 13 students from group II respectively. Table 2 shows the summary of of students' achievements between pre-test and post-test for both groups.

Table 2 Frequency of students' mark improvement from Pre to Post Tests

\begin{tabular}{lccc}
\hline Pre Test marks & Post test marks & Marks improvement & No of students \\
\hline 0 & 0 & 0 & 4 \\
\hline 0 & 1 & +1 & 2 \\
\hline 0 & 2 & +2 & 3 \\
\hline 0 & 3 & +3 & 2 \\
\hline 0 & 4 & +4 & 3 \\
\hline 0 & 5 & +5 & 4 \\
\hline 0 & 6 & +6 & 4 \\
\hline
\end{tabular}

In the pre-test, as expected since all participants are in the low ability group, all the students were unsuccessful in attempting the questions. Out of the 22 students that participated in this study, $50 \%$ demonstrated improvement from their pre-test with scores ranging from 4 to 6 while $31.8 \%$ of them scored either 1,2 or 3 . These students showed significant improvements from their pre-test achievements. There were 4 students who were still unable to factorise correctly, as indicated in the zero scores in the post-test.

Table 3 Paired sample t- test

\begin{tabular}{|c|c|c|c|c|c|c|c|c|}
\hline \multicolumn{9}{|c|}{ Paired Differences } \\
\hline & \multirow[b]{2}{*}{ Mean } & \multirow{2}{*}{$\begin{array}{c}\text { Std. } \\
\text { Deviation }\end{array}$} & \multirow{2}{*}{$\begin{array}{l}\text { Std. } \\
\text { Error } \\
\text { Mean }\end{array}$} & \multicolumn{2}{|c|}{$\begin{array}{l}95 \% \text { Confidence } \\
\text { Interval }\end{array}$} & \multirow[t]{2}{*}{$\mathrm{t}$} & \multirow[t]{2}{*}{$\mathrm{df}$} & \multirow[t]{2}{*}{$\begin{array}{c}\text { Sig. } \\
\text { (2-tailed) }\end{array}$} \\
\hline & & & & Lower & Upper & & & \\
\hline $\begin{array}{l}\text { Pre-test - } \\
\text { Post-test }\end{array}$ & -3.1818 & 2.1960 & 0.4682 & -4.1555 & -2.2082 & -6.796 & 21 & 0.000 \\
\hline
\end{tabular}

Table 3 presents the results from paired sample t-test between the pre- and post-test. The significant (2-tailed) value of $0.00(\mathrm{p}<0.05)$ indicates that there is a significant difference in pre-test and post-test. This means that the implementation of concrete model in learning factorisation does have a positive effect on students' performance.

During the post-test, group I was supplemented with algebra tiles whereas group II had to depend solely on their understanding from the intervention practices. In order to factorise, both groups were given the options to choose any method that they feel comfortable with i.e. cross-multiply or utilising algebra tiles or even both. The percentage of students' options on method(s) used in factorising was simplified using the pie chart representation in Figure 2. 


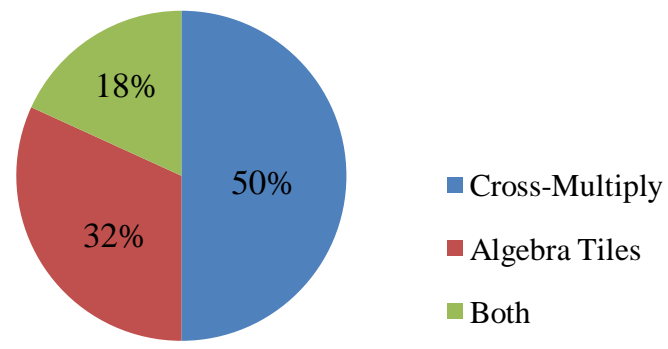

Figure 2 Pie chart of the students' method used in factorisation

Half of the participants in this research study applied cross-multiplication method as their approach to factorisation while $32 \%$ of them utilised algebra tiles and $18 \%$ did both ways.

There were a total of 12 were being interviewed for this study. Due to the time constraint with group I, a small group interview was carried out. However, with group II, a casual one-to-one interview was conducted. These different interview techniques were designed to elicit the same information from all respondents.

Despite all six students in group I acknowledging their poor mathematics skills is due to lack of practices, they agree on the importance of practice in learning mathematics. Regardless of their first experience working with algebra tiles, three of them agreed factorising with the aid of manipulatives was much more easier as they could figure out the answers easily just by evaluating the length and breadth of the rearranged tiles. Half of group I interviewees expressed their burden and hardships in learning mathematics. There were times when they struggled to grasp the mathematics concept especially when the teacher was teaching too fast. Low memory ability was one of their weaknesses as well. With the aid of algebra tiles, it reduced pressure in learning factorisation and the lessons became more enjoyable and less stressful.

In the individual interview of members from group II (approximately 5 to 10 minutes each), majority of them preferred factorising with cross-multiplication method. Among the 6 respondents, half of them were sceptical on learning factorisation with algebra tiles. They found algebra tiles could cause confusion when it involves higher coefficients, as there will be many tiles to rearrange and doubted whether this method would be acceptable in big examination such as in O-Level Examination. Hence they decided to choose cross-multiplication method after all.

\section{Conclusions}

Based on the results and findings discussed earlier, the following research questions are addressed:

Research Question 1: How does the aid of concrete model affect low ability students' achievement on factorising quadratic expression in Brunei Darussalam?

Based on the analysis of students' achievement tests, learning factorisation with the aid of concrete model does have a positive effect on students' performances in the post-test where $81.8 \%$ of them showed improvements from their pre-test. After the interventions, most of them could factorise the quadratic expressions correctly using methods that they are comfortable with. 
Six students who decided to utilise algebra tiles as their means to factorise and the other nine who preferred cross-multiply also performed very well. Some of them may need extra practices with both methods to reduce the tendency to make mistakes in calculation and computation.

Research Question 2: What are students' perceptions on the usefulness and effectiveness of concrete model in learning factorisation of quadratic expression in Brunei Darussalam?

The data collected from student interviews indicated positive feedback from the students. They found that learning mathematics with the aid of concrete model is more enjoyable and it makes mathematics concept easier to grasp. They also gained more confidence in factorising quadratic expressions. This could boost their motivation to learn more and be more engaged in the lesson.

However, there were a few concerns regarding the use of algebra tiles. When higher coefficients are involved, it may cause difficulty and confusion to rearrange/draw the algebra tiles into rectangular shape because there are so many tiles involved. The students were afraid this manipulation of algebra tiles would not be acceptable during exams.

Overall, the majority of them agreed that the aid of concrete model does help their learning in factorisation.

\section{Implications and Recommendations}

For future study, researchers can consider expanding the use of concrete model in mathematics learning to other algebra topics. Mathematics students, especially the low ability ones, find algebra as one of the hardest topics because the concepts are too abstract. It would be interesting to see how concrete model could improve their algebraic learning. However, the data collected from this study was not ample enough to determine anything about the effectiveness of it.

It would also be helpful if the studycould be conducted over a longer period of time, as low ability students may need more time to fully grasp the concept of concrete model. Also, as this study only involved a small population of students consisting of all boys, it would be more beneficial for future researchers to do this study at both all-girls andco-edsecondary schools for comparison and reliability purposes.

\section{References}

Badarudin, B. R., and Khalid, M., 2008, Using the jar model to improve students' understanding of operations on integers. In D. D. Bork, B. D. Sondergaard, B. G. Alfonso, \& C. C. L. Cheng (Eds.), Proceedings of $11^{\text {th }}$ International Congress on Mathematical Education, Belgium, pp. 85-94.

Boggan, M., Harper, S., andWhitmire, A. 2010, Using manipulatives to teach elementary mathematics. Journal of Instructional Pedagogies, 1-6.

Cohen, D., and Crabtree, B., 2006, Qualitative research guidelines project.Date of access: 21/5/2015. http://www.qualres.org/HomeSemi-3629.html

Gulkilik, H., andArikan, A., 2012, Preservice secondary mathematics teachers' views about using multiple representations in mathematics instruction. Procedia-Social and Behavioral Sciences, 47, 1751-1756.

Hinzman, K. P., 1997, Use of manipulatives in mathematics at the middle school level and their effects on students' grades and attitudes. Masters thesis, ERIC database record no. ED411150.

Kotsopoulos, D., 2007, Unraveling students challenges with quadratics: A cognitive approach. Australian Mathematics Teacher, 63(2), 19-24. 
McClung, L. W., 1998, A study on the use of manipulatives and their effect onstudent achievement in a high school algebra I class. Masters thesis, ERIC database record no. ED425077.

Ministry of Education, 2013, The National Education System for the $21^{\text {st }}$ Century: SPN21 (Revised ed.). (Brunei Darussalam: Ministry of Education).

Moyer, P. S., 2001, Are we having fun yet? How teachers use manipulatives to teach mathematics. Educational Studies in Mathematics, 47, 175-197.

Peppers, D. S., Wan, A., and Phillips, H. E., 2014, A closer look at manipulatives in remediation. Mathematics Teaching in the Middle School, 20(3), 166-173.

Robert, S. K., 2010, On my mind: The conceptual chicken and the procedural egg. Mathematics Teaching in the Middle School, 16, 196-198.

Shaw, J. M., 2002, Manipulatives enhance the learning of mathematics. Houghton Mifflin Mathematics. Date of access: 21/6/2015. http://www.eduplace.com/state/pdf/author/shaw.pdf

Yahya, N., and Shahrill, M., 2014, The strategies used in solving algebra by secondary school repeating students. Paper presented at the $5^{\text {th }}$ World Conference on Learning, Teaching and Educational Leadership (WCLTA 2014), Prague, Czech Republic. 